\title{
Relationships between the Curing Conditions and Some Mechanical Properties of Hybrid Thermosetting Materials
}

\author{
Newton L. Dias Filho, ${ }^{*, a}$ Celso X. Cardoso ${ }^{b}$ and Hermes A. de Aquino ${ }^{a}$ \\ ${ }^{a}$ Departamento de Física e Química, Universidade Estadual Paulista, Av. Brasil, 56, Centro, CP 31, \\ 15385-000 Ilha Solteira- SP, Brazil \\ ${ }^{b}$ Departamento de Física, Química e Biologia, Universidade Estadual Paulista, Rua Roberto Simonsen, 305, \\ 19060-900 Presidente Prudente-SP, Brazil
}

\begin{abstract}
Foi investigada a relação entre os parâmetros calor de polimerização $(\Delta \mathrm{H})$ e energia de ativação ( $E_{\mathrm{a}}$ ) obtidos por calorimetria diferencial de varredura (DSC) e a proporção entre resina epóxi e endurecedor de polímeros termorrígidos baseados em uma resina epóxi híbrida orgânicainorgânica $(\mathrm{OG})$. A energia de ativação $\left(\mathrm{E}_{\mathrm{a}}\right)$ e o calor de polimerização $(\Delta \mathrm{H})$ aumentaram com o aumento do conteúdo de OG até $70 \%$ em massa. Um aumento adicional no conteúdo de OG até $80 \%$ reduziu $\mathrm{E}_{\mathrm{a}}$ e $\Delta \mathrm{H}$. A análise dinâmico-mecânica sugere que a máxima densidade de ligações cruzadas é obtida em $83 \%$ de OG, enquanto as propriedades mecânicas de resistência à fratura e módulo de tensão são maximizadas em tôrno de $70 \%$ de OG.
\end{abstract}

The relationship between the heat of polymerization $(\Delta \mathrm{H})$ and activation energy $\left(\mathrm{E}_{\mathrm{a}}\right)$ parameters, obtained by differential scanning calorimetry (DSC) and the ratio of epoxy resin to hardener of the thermosetting materials based on an organic-inorganic hybrid epoxy resin (OG) was investigated. Activation energy $\left(\mathrm{E}_{\mathrm{a}}\right)$ and heat of polymerization $(\Delta \mathrm{H})$ increased with an increasing OG content, up to $70 \mathrm{wt} \%$. Further increase in OG content to $80 \mathrm{wt} \%$ reduced $\mathrm{E}_{\mathrm{a}}$ and $\Delta \mathrm{H}$. Dynamic mechanical analysis indicates that the maximum cross-link density is obtained at $83 \mathrm{wt} \%$ OG, whereas fracture toughness and tensile modulus mechanical properties are maximized at $70 \mathrm{wt} \% \mathrm{OG}$.

Keywords: differential scanning calorimetry, siloxane, epoxy resin, silsesquioxanes, nanocomposites

\section{Introduction}

Epoxy resins are one of the most important classes of thermosetting polymers used for structural and adhesive applications. ${ }^{1-5}$ However, the current problems in engineering applications of epoxy thermosets include poor resistance to crack propagation because they are brittle. ${ }^{6,7}$ To overcome brittleness, among other additives of the multi-component formulation of the epoxy resin, a toughening agent is often used, such as fillers, polyhedral oligosilsesquioxanes, dendrimers etc. $^{8-18}$

Methods of appropriately mixing two or more different materials, such as inorganic and organic, to obtain a new hybrid material with desirable features have been developed. ${ }^{19-23}$

*e-mail: nldias@dfq.feis.unesp.br
Polymerization of the hybrid epoxy resin studied in this work, which is a nanosized epoxy resin, can lead to nanocomposite materials. In these materials the cubes of the cubic siloxane can be connected one another by organic components with known architecture and lengths of the order of 3-5 nm, forming composites with a completely defined interfacial component between the organic and inorganic phase. ${ }^{19-23}$ This hybrid epoxy resin can be classified as a polyhedral oligomeric silsesquioxane, where the cubic silica cores are "hard particles" rigid with 0.53 $\mathrm{nm}$ diameter and a spherical radius of 1-3 nm including the peripheral organic units. ${ }^{14-18}$

It is known that different types of epoxy resins and curing conditions confer different characteristic properties. The purpose of this work is to apply a DSC technique to study the relationships between the curing conditions and some mechanical properties of the hybrid thermosetting materials. 


\section{Experimental}

\section{Materials}

Tetraethoxysilane $\left[\mathrm{Si}(\mathrm{OEt})_{4}\right]$, tetramethylammonium hydroxide $\left[\left(\mathrm{CH}_{3}\right)_{4} \mathrm{NOH}\right]$, dimethylchlorosilane $\left[\mathrm{HSi}\left(\mathrm{CH}_{3}\right)_{2} \mathrm{Cl}\right]$, allyl glycidyl ether, and platinum dicyclopentadieno $[\mathrm{Pt}(\mathrm{dcp})]$, triphenylphosphine and methylenedianiline were purchased from Aldrich Chemical Company and used as received. Hexane and methanol was purchased from Lancaster Synthesis Company and used without further purification.

\section{Synthesis of octaanion solution, $\left[\mathrm{Me}_{4} \mathrm{~N}^{+}\right]_{8}\left[\mathrm{SiO}_{2.5}{ }^{-}\right]_{8}$}

$\left[\mathrm{Me}_{4} \mathrm{~N}^{+}\right]_{8}\left[\mathrm{SiO}_{2.5}{ }^{-}\right]_{8}$ was synthesized following a procedure previously reported, as described below. ${ }^{19,24-27} \mathrm{~A}$ schematic representation of this reaction is shown in Figure 1. To a $2 \mathrm{~L}$ round bottom flask equipped with a magnetic stir bar, were added $800.8 \mathrm{~mL}(7.60 \mathrm{~mol})$ tetramethylammonium hydroxide ( $25 \mathrm{wt} \%$ in methanol), $390.8 \mathrm{~mL}$ (9.92 mol) methanol, and $292.8 \mathrm{~mL}$ (16.26 mol) distilled water. The flask was cooled in an ice bath, and the system was maintained under nitrogen. Then $428 \mathrm{~mL}$ (1.91 mol) tetraethoxysilane was added via an addition funnel. The solution turned cloudy and was allowed to stir at room temperature overnight to produce a clear solution of tetramethylammonium octaanion in quantitative yield.

This solution was characterized by ${ }^{29} \mathrm{Si} \mathrm{NMR}$, that showed one peak at $\delta-99.4 \mathrm{ppm}$.

Synthesis of octa[hydridodimethylsiloxy] octasiloxane, $\left[\mathrm{HMe}_{2} \mathrm{SiOSiO}_{1.5}\right]$

$\left[\mathrm{HMe}_{2} \mathrm{SiOSiO}_{1.5}\right]$ was also synthesized following published procedures, as it is described below. ${ }^{19,24-27}$ Figure 1 shows a schematic representation for this reaction.

To a $5 \mathrm{~L}$ bottom flask equipped with a mechanical stirrer, were added $2600 \mathrm{~mL}$ hexane and $436 \mathrm{~mL}$ (4.0 mol) dimethylchlorosilane under nitrogen. The flask was placed in an ice bath and $1000 \mathrm{~mL}$ of the octaanion solution was

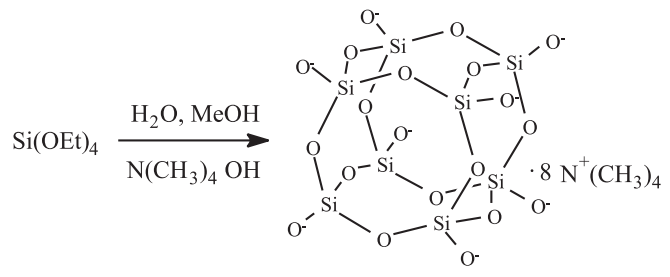

$$
\left[\mathrm{Me}_{4} \mathrm{~N}^{+}\right]_{8}\left[\mathrm{SiO}_{2.5}{ }^{-}\right]_{8}
$$

then added via an addition funnel, over a $2 \mathrm{~h}$ period. The final mixture was stirred continuously for another $2 \mathrm{~h}$. The two layers were separated with a separatory funnel. The hexane layer was dried over sodium sulfate and gravity filtered, followed by solvent removal by rotary evaporation to yield a white powder. This powder was rinsed with methanol and collected by vacuum filtration. The product was dried in a vacuum oven at $70{ }^{\circ} \mathrm{C}$ for $5 \mathrm{~h}$, obtaining a white powder in $89 \mathrm{~g}$ yield, which was $70 \%$ of theoretical.

${ }^{1} \mathrm{H}$ NMR showed a multiplet at $\delta 4.73\left(\mathrm{~m}, 8 \mathrm{H}, \mathrm{CH}_{3}-\right.$ $\mathrm{Si}-\underline{\mathrm{H}})$ and doublet at $0.26,0.25 \mathrm{ppm}\left(\mathrm{d}, 48 \mathrm{H}, \mathrm{CH}_{3}-\mathrm{Si}-\mathrm{H}\right)$ ppm. ${ }^{13} \mathrm{C}$ NMR revealed one peak at $\delta 0.059 \mathrm{ppm}(\mathrm{H}-\mathrm{Si}-$ $\left.\underline{\mathrm{CH}}_{3}\right) .{ }^{29} \mathrm{Si} \mathrm{NMR}$ showed two peaks at $\delta-2.897 \mathrm{ppm}(\mathrm{H}-$ $\left.\underline{\mathrm{Si}}-\mathrm{CH}_{3}\right)$ and -108.697 ppm $\left(\underline{\mathrm{Si}}-\mathrm{O}_{4}\right)$. SEC: $\mathrm{Mn}=995, \mathrm{Mw}$ $=1008, \mathrm{PDI}=1.01$, calculated $\mathrm{MW}=1017 \mathrm{~g} \mathrm{~mol}^{-1}$. FTIR (KBr) $v_{\max } / \mathrm{cm}^{-1}: 2966$ (v C-H), 2144 (v Si-H), 1420 (v C$\mathrm{H}), 1258$ ( $\left.\mathrm{v} \mathrm{Si}-\mathrm{CH}_{3}\right), 1096$ ( $\left.v \mathrm{Si}-\mathrm{O}\right)$.

Synthesis of octa[dimethylsiloxypropylglycidylether] octasiloxane (OG)

The synthesis of OG followed published procedures, as described below. ${ }^{19,27}$ A schematic representation for this reaction is showed in the Figure 2.

To a $500 \mathrm{~mL}$ schlenk flask equipped with a magnetic stir bar and a condenser, was added $120.0 \mathrm{~g}$ (0.12 mol) octahydrido spacer cube, $\left[\mathrm{HMe}_{2} \mathrm{SiOSiO}_{1.5}\right]$. The flask was evacuated and refilled with $\mathrm{N}_{2}$ gas three times at $50{ }^{\circ} \mathrm{C}$. Then $132.0 \mathrm{~mL}(0.99 \mathrm{~mol})$ allyl glycidyl ether was added to the solution followed by $0.3 \mathrm{~mL}$ of $2.0 \mathrm{mmol} \mathrm{L}^{-1}$ solution of platinum dicyclopentadieno $[\mathrm{Pt}(\mathrm{dcp})]$ and the reaction was heated at $90{ }^{\circ} \mathrm{C}$. Triphenylphosphine, $10 \mathrm{mg}$, was then added to deactivate the $[\mathrm{Pt}(\mathrm{dcp})]$ catalyst and the toluene solvent was removed by rotary-evaporation. Yield: $210 \mathrm{~g}$ (91\% of theoretical).

This material was characterized as follows. ${ }^{1} \mathrm{H}$ NMR $\left(\mathrm{CDCl}_{3}\right) \delta \mathrm{CH}_{2} \mathrm{O}\left(\mathrm{CH}_{2}\right)_{3}$ diastereotopic 3.55, 3.30 (dd, J 3.27 $\mathrm{Hz}, 8 \mathrm{H}$ ) (due to peak overlap, all resonances between 3.34 and 3.16 are integrated as two peaks, 24H), 3.30, 3.28 (dd, $J 2.89 \mathrm{~Hz}$ ), $\mathrm{SiCH}_{2} \mathrm{CH}_{2} \mathrm{CH}_{2} \mathrm{O} 3.18$ (m, 8H), OCH $\mathrm{CH}_{2}$ (epoxy) $2.94(\mathrm{~m}, 8 \mathrm{H}), \mathrm{CH}_{2}$ (epoxy) diastereotopic 2.58 (dd, 8H),

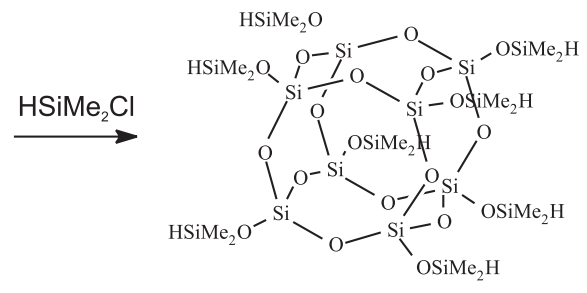

$\left[\mathrm{HMe}_{2} \mathrm{SiOSiO}_{1.5}\right]$

Figure 1. Schematic representation of preparation of the octaanion solution, $\left[\mathrm{Me}_{4} \mathrm{~N}^{+}\right]_{8}\left[\mathrm{SiO}_{25}{ }^{-}\right]_{8}$, and of the octa[hydridodimethylsiloxy] octasiloxane, $\left[\mathrm{HMe}_{2} \mathrm{SiOSiO}_{1.5}\right]$. 


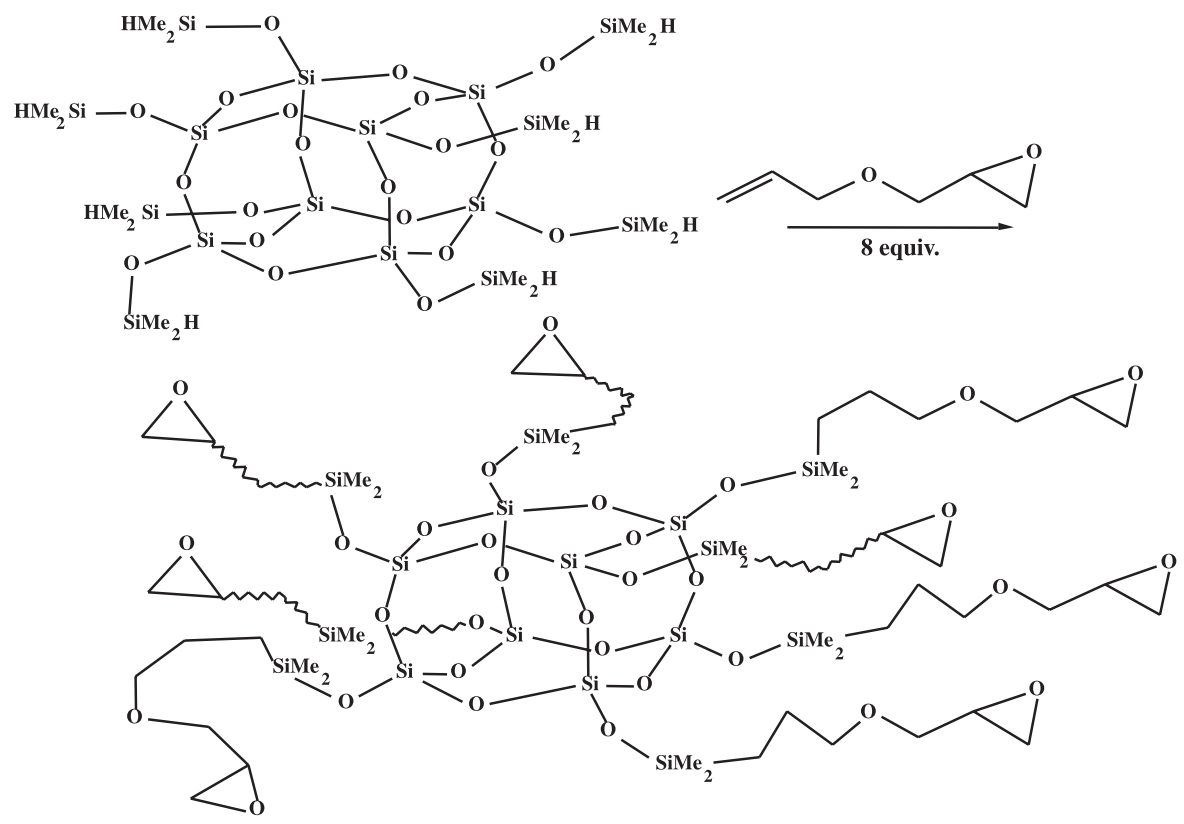

Figure 2. Reaction of preparation of the octa[dimethylsiloxypropylglycidylether] octasiloxane (OG).

$2.40(\mathrm{dd}, \quad 8 \mathrm{H}), \quad \mathrm{SiCH}_{2} \mathrm{CH}_{2} \mathrm{CH}_{2} \mathrm{O} 1.48(\mathrm{~m}, 16 \mathrm{H})$, $\mathrm{SiC}_{2} \mathrm{CH}_{2} \mathrm{CH}_{2} \mathrm{O} 0.47(\mathrm{~m}, 16 \mathrm{H}),\left(\mathrm{C}_{3}\right)_{2} \mathrm{SiCH}_{2} 0.00 \mathrm{ppm}(\mathrm{s}$, $48 \mathrm{H}) .{ }^{13} \mathrm{C} \mathrm{NMR}\left(\mathrm{CHCl}_{3}\right) \delta \mathrm{SiCH}_{2} \mathrm{CH}_{2} \underline{\mathrm{C}}_{2} \mathrm{O} 74.29$, $\mathrm{CH}_{2} \mathrm{O}\left(\mathrm{CH}_{2}\right)_{3} 71.86, \mathrm{OCH}_{2} \mathrm{CH}$ (epoxy) 51.11, $\underline{\mathrm{CH}}_{2}$ (epoxy) 44.35, $\mathrm{SiCH}_{2} \mathrm{CH}_{2} \mathrm{CH}_{2} \mathrm{O} 23.59, \mathrm{SiCH}_{2} \mathrm{CH}_{2} \mathrm{CH}_{2} \mathrm{O}$ 13.93, $\left(\mathrm{CH}_{3}\right)_{2} \mathrm{SiCH}_{2} 0.00$ ppm. ${ }^{29} \mathrm{Si} \mathrm{NMR}\left(\mathrm{C}_{6} \mathrm{D}_{6}\right) \delta\left(\mathrm{CH}_{3}\right)_{2} \underline{\mathrm{SiCH}}_{2}$ -7.3, $\underline{\mathrm{SiOSi}}\left(\mathrm{CH}_{3}\right)_{2} \mathrm{CH}_{2}-129.4$ ppm. SEC: $\mathrm{Mn}=1850, \mathrm{Mw}$ $=1898, \mathrm{PDI}=1.02$, calculated $\mathrm{MW}=1931 \mathrm{~g} \mathrm{~mol}^{-1}$.

FT-IR (neat film) $v_{\max } / \mathrm{cm}^{-1}:(\mathrm{C}-\mathrm{H}) 3035,2962,2934$, 2874 (m); (Si-H) 2142 (m); (Si-CH ${ }_{3}$ and C-O) 1250-1260 (s); (Si-O) 1095 (vs); (C-O-C) 902 (s).

\section{Curing process}

The hybrid epoxy resin (OG) is a viscous liquid and the curing agent 3,3-methylenedianiline (MDA) is solid at room temperature. The structures of the OG and MDA are shown in Figure 3.

In the present investigation, samples having different amount of OG and MDA were prepared. In formulating samples, the molar ratio $f$ is defined as the ratio of epoxy ring to amine hydrogen $(\phi=$ no. of epoxy rings in OG/ No. of amine hydrogen in MDA).

A conventional stoichiometric ratio of 1 mol of epoxy resin in OG (1 mol of OG contain $8 \mathrm{~mol}$ of epoxy rings) to $2 \mathrm{~mol}$ of amine ( $2 \mathrm{~mol}$ of MDA contain 8 amine hydrogen) would occur for $\phi=1$. Thus, when $\phi=1$, the two components are mixed at stoichiometric amount of $83 \mathrm{wt} \%$ of OG and $17 \mathrm{wt} \%$ of MDA.

For curing optimization tests, samples were cured at different temperatures and times to study the cure condition.

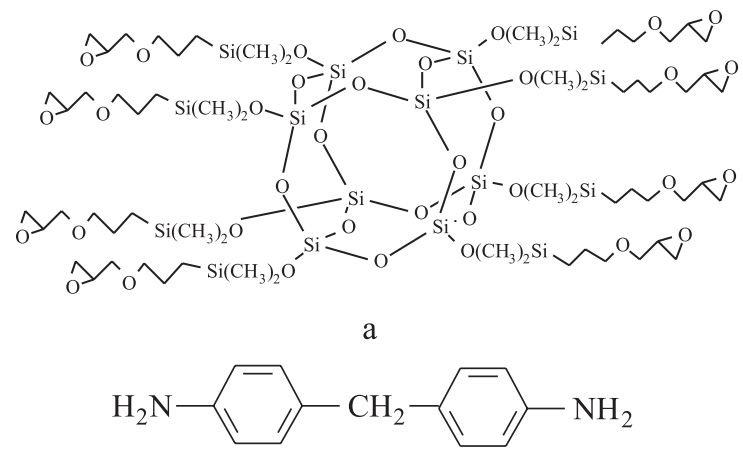

b

Figure 3. Components of the curing reaction: (a) OG; (b) 3,3methylenedianiline (MDA).

OG/MDA samples were cured in the temperature range of 100- $200{ }^{\circ} \mathrm{C}$ and for periods of 2 to $12 \mathrm{~h}$. In the present study curing for $10 \mathrm{~h}$ at $150{ }^{\circ} \mathrm{C}$ was adopted for the composites OG/MDA.

OG and MDA were weighed into an aluminum pan with a diameter of $61.5 \mathrm{~mm}$ and depth of $18 \mathrm{~mm}$ and mixed by hand at room temperature. The mixture was then put into an oven preheated to $\sim 150{ }^{\circ} \mathrm{C}$ under vaccum. After degassing for 10-15 min and no more bubbles emerged from the mixture, the content was transferred to an aluminum mold preheated to $150{ }^{\circ} \mathrm{C}$. It is not observed any reaction during vacuum degassing at $150{ }^{\circ} \mathrm{C}$. The filled mold was placed in an oven and heated under nitrogen for $10 \mathrm{~h}$ at $150{ }^{\circ} \mathrm{C}$ for curing the mixture. After the mold cooled, the sample was removed and kept in a sealed desiccator before the dielectric analysis and mechanical tests were performed. 
The compositions of samples are shown in Table 1. A schematic representation of composites with discontinuous organic-inorganic phases from cubic silsesquioxane is shown in Figure 4.

Table 1. Formulations for OG/MDA composites

\begin{tabular}{lccc}
\hline wt\% OG & wt\% MDA & $\phi^{*}$ & $\begin{array}{c}\text { Molar ratio } \\
\text { MDA/OG }\end{array}$ \\
\hline 95 & 5 & 3.90 & 0.51 \\
91 & 9 & 2.07 & 0.96 \\
87 & 13 & 1.37 & 1.46 \\
83 & 17 & 1.00 & 1.99 \\
80 & 20 & 0.82 & 2.44 \\
79 & 21 & 0.77 & 2.59 \\
77 & 23 & 0.69 & 2.91 \\
73 & 27 & 0.55 & 3.60 \\
70 & 30 & 0.48 & 4.18 \\
68 & 32 & 0.44 & 4.58 \\
67 & 33 & 0.42 & 4.79 \\
63 & 37 & 0.35 & 5.72 \\
60 & 40 & 0.31 & 6.49 \\
55 & 45 & 0.25 & 7.96 \\
50 & 50 & 0.20 & 9.74 \\
40 & 60 & 0.14 & 14.62 \\
30 & 70 & 0.09 & 22.78 \\
20 & 80 & 0.05 & 38.80 \\
\hline
\end{tabular}

*In formulating samples, the molar ratio $\mathrm{f}$ is defined as the ratio of epoxy ring to amine hydrogen $(\phi=$ number of epoxy rings in OG/number of amine hydrogen in MDA).

\section{Mechanical testing}

Samples removed from the aluminum mold had rough edges due to the overflow of polymer. These edges were polished using a polish wheel with 120-grit SiC paper. After polishing, the samples were ready for mechanical testing. The average dimensions of the samples were
$3.0 \times 13.0 \times 170 \mathrm{~mm}$. (errors $< \pm 0.2$ for width and thickness and $< \pm 0.4$ for length).

The elastic moduli (tensile moduli), E, data were obtained using an Instron 4502 screw driven mechanical testing machine. The dimensions of each sample were determined by measuring the width and thickness at three points along the gauge length prior to the test. These were used to calculate the averages of width and thickness for each sample. The elastic moduli were obtained following ASTM standard [No. E111(1997)]. The samples were clamped using anti-slackening screw grips with added friction increasing pads. Care was taken to ensure that the tensile and sample axes were co-axial. The cross-head displacement rate was set at $1 \mathrm{~mm} \mathrm{~min}^{-1}$. The tensile tests were stopped when the samples were in the elastic deformation region. Usually, tests were stopped at loads of about $200-250$ N. Samples with very low modulus would break before reaching this load. The data acquisition software collected load-displacement data points at a speed of 2 points per second.

The critical stress intensity factor (fracture toughness) was obtained following ASTM standard [No. E399(1990)]. This standard requires that the ratio of width to thickness be between two and four, and the ratio of the pre-crack to sample between 0.45 and 0.55 . The pre-crack was introduced using a fresh razor blade tapped into a square notch sawed to $0.1-0.2$ of the sample width. This method introduces a natural crack into the sample. Then the sample was loaded into the testing apparatus in the same manner as described above for Young's modulus measurements. The sample was then loaded to failure and the breaking load recorded. The critical stress intensity factor was determined from the standard relationships:

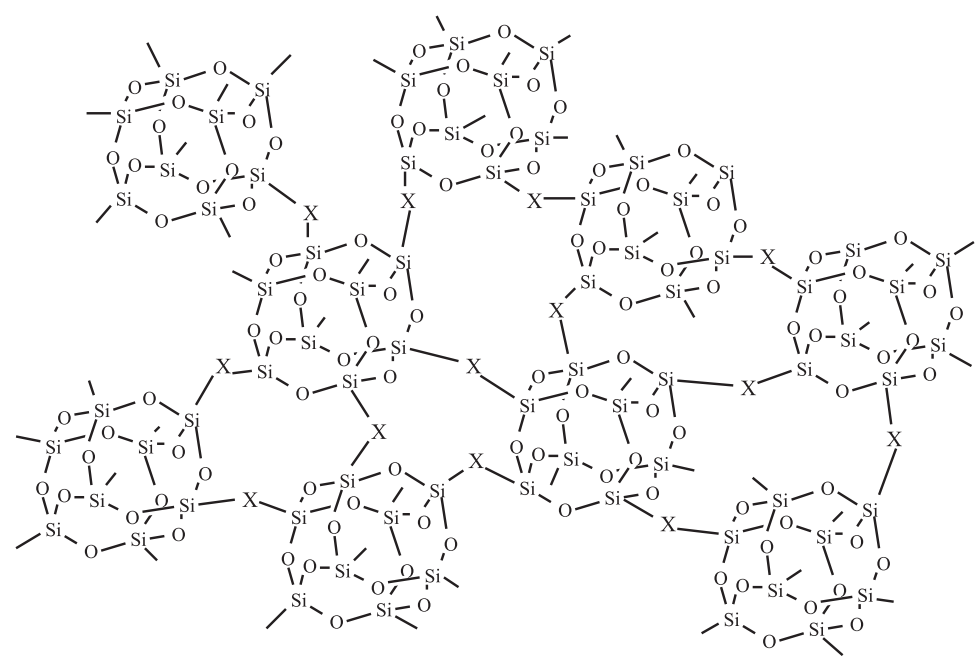

Figure 4. Scheme of a general representation of composites with discontinuous organic-organic phases from cubic silsesquioxane. $\mathrm{X}=$ links between cubes. 
$K_{I C}=Y \sigma_{0} a^{1 / 2}$

$Y=\left[1.99-0.41\left(\frac{a}{w}\right)+18.70\left(\frac{a}{w}\right)^{2}-38.48\left(\frac{a}{w}\right)^{3}+53.85\left(\frac{a}{w}\right)^{4}\right]$

$\sigma_{0}=\frac{P_{b}}{B w}$

where $P_{b}$ is the load at break, $B$ is the sample thickness, $w$ is the sample width, and $a$ is the pre-crack length.

\section{NMR and FTIR Analyses}

Solution NMR Analyses. All ${ }^{1} \mathrm{H}$ and ${ }^{13} \mathrm{C}$ NMR analyses were done in $\mathrm{CDCl}_{3}$ and recorded on a BRUKER DRX 400 spectrometer. ${ }^{13} \mathrm{C}$ NMR spectra were obtained at $100.6 \mathrm{MHz}$ using a $27027 \mathrm{~Hz}$ spectral width, and a relaxation delay of $0.6 \mathrm{~s} .{ }^{1} \mathrm{H}$ NMR spectra were collected at $400.1 \mathrm{MHz}$, using a $3591 \mathrm{~Hz}$ spectral width, and a relaxation delay of $1 \mathrm{~s}$.

Solid state NMR analyses. All ${ }^{29} \mathrm{Si}-\mathrm{NMR}(59.5 \mathrm{MHz})$ and ${ }^{13} \mathrm{C}$ NMR (75.4 MHz) solid state analyses were recorded on a Varian INOVA 300 spectrometer. The samples were packed in zirconia rotors and spun at the magic angle at $4500 \mathrm{~Hz}$, after a relaxation delay of 10.0 and $6.0 \mathrm{~s}$ for ${ }^{29} \mathrm{Si}$ and ${ }^{13} \mathrm{C}$ respectively. All chemical shifts are reported in units (ppm) using TMS as external reference.

Gel permeation chromatography (GPC). GPC data were measured using a Waters GPC system, equipped with RI and UV detectors, a Styragel column set, and a data capture unite. The system was calibrated using polystyrene standards, with THF used as the eluent.

Fourier transform infrared spectra was recorded on a Nicolet 5DXB FT-IR 300 spectrometer. About $600 \mathrm{mg}$ of $\mathrm{KBr}$ were ground in a mortar and pestle, and a sufficient quantity of the solid sample was ground with $\mathrm{KBr}$ to produce a $1 \mathrm{wt} \%$ mixture resulting in pellets. Liquid samples were cast on salt plates. A minimum of 32 scans was collected at a resolution of $\pm 4 \mathrm{~cm}^{-1}$.

\section{Differential Scanning Calorimetry (DSC)}

Curing behavior of OG with MDA was monitored with a Perkin-Elmer DSC7 type differential scanning calorimeter, at temperatures ranging from 25 to $200{ }^{\circ} \mathrm{C}$. The resin/hardener mixture $(18-22 \mathrm{mg})$ was heated in aluminum pans at a heating rate of $10{ }^{\circ} \mathrm{C} \mathrm{min}-1$ in nitrogen atmosphere or in static air atmosphere. Pure indium was used as a standard for calorimetric calibration. Runs were carried out using an empty cell as a reference. The heat flow data, as a function of temperature and time, were obtained using the area under the peak of the exotherm.
Dynamic Mechanical Analysis (DMA)

DMA was performed on cured samples using a Netzsch DMA 242 instrument operating at $1 \mathrm{~Hz}$ in the three-point bending mode at a heating rate of $5^{\circ} \mathrm{C} \mathrm{min}^{-1}$. The dimensions of the specimens were $\sim 3.1 \times 10 \times 100 \mathrm{~mm}$. Dynamic mechanical spectra were obtained from -50 to $200{ }^{\circ} \mathrm{C}$.

\section{Results and Discussion}

\section{Curing parameters from DSC}

Differential scanning calorimetry (DSC) has been extensively used to study the curing reaction kinetics of various thermosetting polymers. ${ }^{28}$ DSC measures the heat flow of the sample as a function of temperature. The basic assumption for the application of DSC technique to the cure of the thermoset composites is that the rate of the kinetics process $(\mathrm{d} \alpha / \mathrm{dt})$ is proportional to the measured heat flow $(\mathrm{dH} / \mathrm{dt}),{ }^{29-31}$ or,

$\mathrm{d} \alpha / \mathrm{dt}=\mathrm{dH} / \mathrm{dt}$

where $\mathrm{H}$ is the enthalpy of the curing reaction.

Without knowing the exact reaction mechanism, it is reasonable to assume that the kinetics parameters of the curing process at a given time $t$ is only a function of the conversion fraction $\alpha$, or,

$\mathrm{d} \alpha / \mathrm{dt}=\mathrm{K}_{(\mathrm{T})} f(\alpha)$

where $\mathrm{K}_{(\mathrm{T})}$ is the temperature-dependent reaction rate constant, which is usually assumed to be of the Arrhenius form, and $f(\alpha)$ is a dependent kinetic model function.

Therefore, the rate constant $\mathrm{K}_{(\mathrm{T})}$ is dependent on temperature and follows a relationship of Arrhenius type as in equation (3),

$\mathrm{K}_{(\mathrm{T})}=\mathrm{Z} \exp \left[-\mathrm{E}_{\mathrm{a}} / \mathrm{RT}\right]$

where $\mathrm{Z}$ is the pre-exponential factor, $\mathrm{R}$ the universal gas constant $\left(8.314 \mathrm{~J} \mathrm{~mol}^{-1} \mathrm{~K}\right)$, and $\mathrm{T}$ is the absolute temperature.

The kinetic parameters of the curing reaction, with special reference to such as $\mathrm{E}_{\mathrm{a}}$, can be calculated using various computational methods. ${ }^{32}$ As it is well known, the reaction between epoxies and amines involves several steps ${ }^{33}$ and hence the kinetics may be rather complex. Without knowing the exact reaction mechanism, it is reasonable to assume that the kinetic parameters of the curing process can be described by the Borchardt and 
Daniels method, ${ }^{32}$ in which the reaction rate at a given time $t$ is a function of the conversion fraction $\alpha$, or

$\mathrm{d} \alpha / \mathrm{dt}=\mathrm{K}_{(\mathrm{T})}(1-\alpha)^{\mathrm{n}}$

where $\mathrm{n}$ is the reaction order kinetic, and $\mathrm{K}_{(\mathrm{T})}$ is the temperature-dependent reaction rate constant.

The reaction rate $(\mathrm{d} \alpha / \mathrm{dt})$ was obtained by dividing the peak height at temperature $\mathrm{T}$ by the total peak area. The unreacted fraction $(1-\alpha)$ was obtained by measuring the ratio of the partial area at temperature $\mathrm{T}$ to the total peak area and subtracting it from unity. The reaction order $n$ and $\mathrm{K}_{(\mathrm{T})}$ were obtained from the plot of $\log \mathrm{d} \alpha / \mathrm{dt}$ versus $\log (1-\alpha)$.

The Borchardt and Daniels method ${ }^{32}$ assumes that the apparent activation energy, $E_{a}$, can be calculated using the Arrhenius expression,

$\ln \mathrm{K}_{(\mathrm{T})}=\ln (\mathrm{Z})-\mathrm{E}_{\mathrm{a}} / \mathrm{RT}$

From the slope of a linear-fit line, the activation energy, $\mathrm{E}_{\mathrm{a}}$ can be calculated, i.e., the slope of $\ln \left(\mathrm{K}_{(\mathrm{T})}\right)$ versus $1 / \mathrm{T}$ gives the value of $\mathrm{E}_{\mathrm{a}}$. The best fit was obtained using $\mathrm{n} \cong$ 2 , indicating that the curing reaction follows a secondorder kinetcs.

Figure 5 plots several DSC curves of the OG/MDA composites obtained at temperatures ranging from 100 to $200{ }^{\circ} \mathrm{C}$

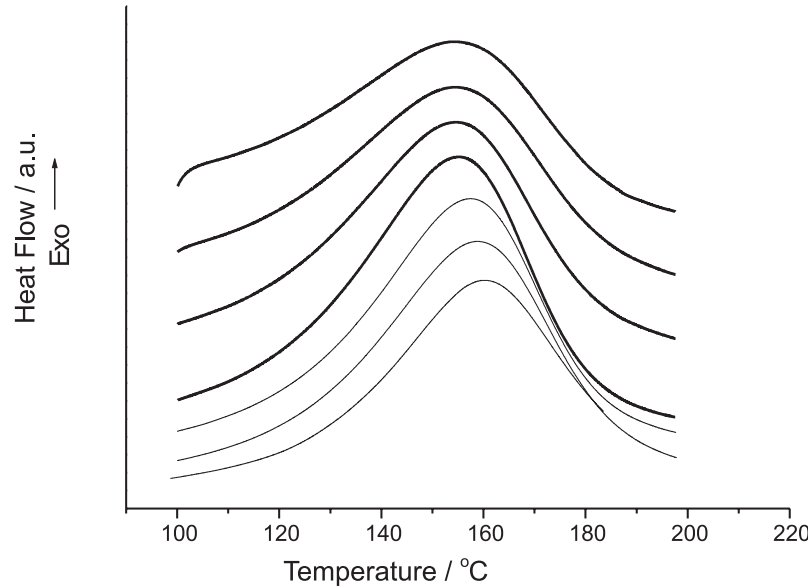

Figure 5. DSC curves for OG/MDA composites at several OG contents: $20,30,40,50,60,70,80 \mathrm{wt} \%$, from bottom to top.

Arrhenius plots from DSC scans recorded for the cured samples using equation 2 are straight lines, the slope $\left(E_{a} /\right.$ $\mathrm{R})$ of which gives the value of $\mathrm{E}_{\mathrm{a}}$, as shown in Figure 6 .

The curves of heat of polymerization $(\Delta \mathrm{H})$ and activation energy $\left(\mathrm{E}_{\mathrm{a}}\right)$ versus $\mathrm{OG}$ content are shown in Figures 7 and 8, respectively. Both curves of $\Delta \mathrm{H}$ and $\mathrm{E}_{\mathrm{a}}$ show the same profile with respect to OG content. They

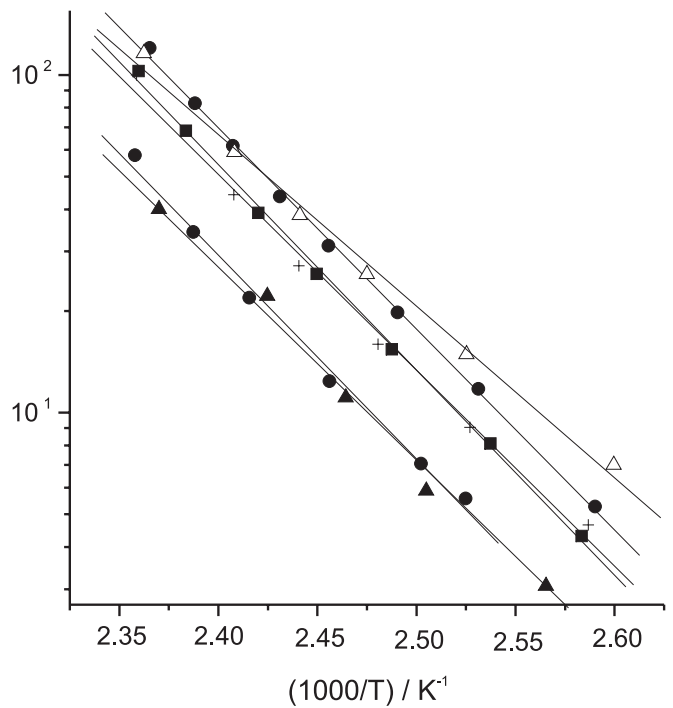

Figure 6. Arrhenius plots for OG/MDA composites at several OG contents (wt\%): $\Delta 20,+30, \bullet 40,-60, \bullet 70$. In this figure $\mathrm{K}_{(\mathrm{T})}$ is plotted on a ln-scale against 1000/T. The slope of the linear fit is $E_{a} / R$.

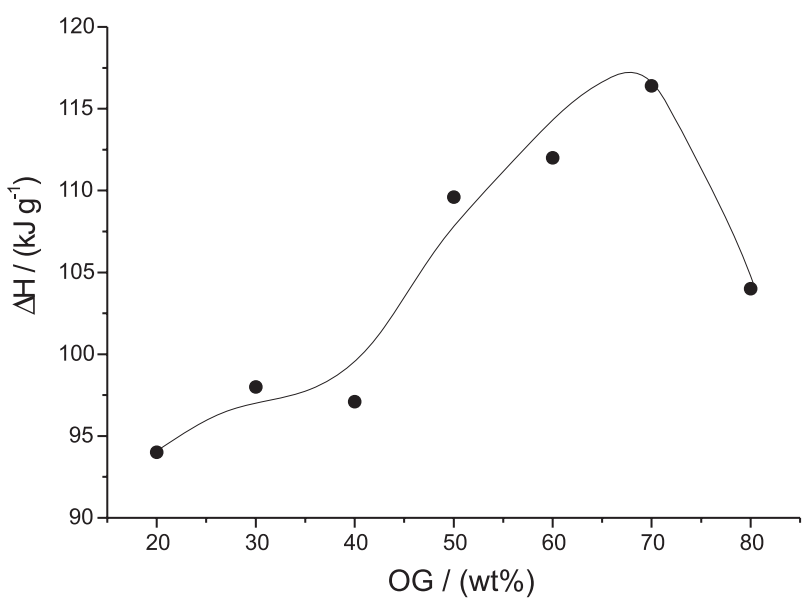

Figure 7. Heat of polymerization $(\Delta \mathrm{H})$ for $\mathrm{OG} / \mathrm{MDA}$ composites versus OG content.

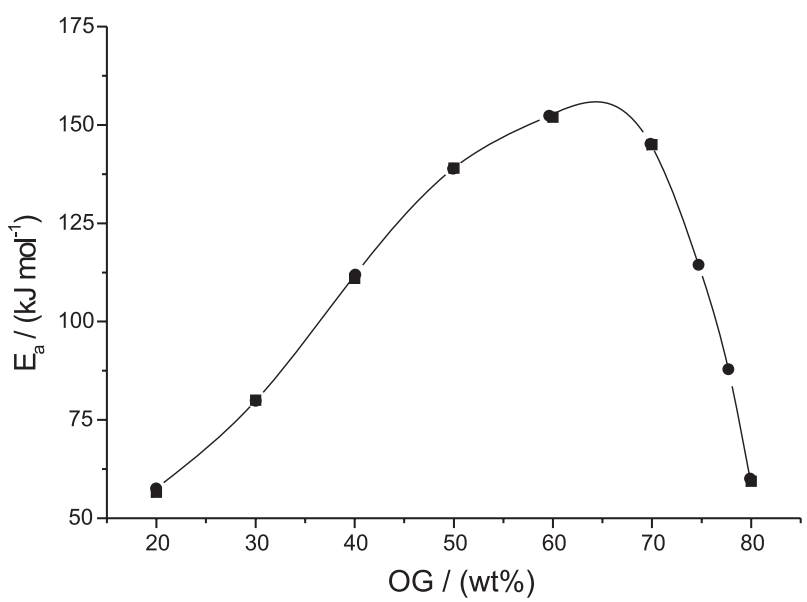

Figure 8. Activation energy ( $\mathrm{E}_{2}$ ) for OG/MDA composites versus $\mathrm{OG}$ content. 
exhibit maxima in the region of $\sim 70 \mathrm{wt} \%$ OG. $\mathrm{E}_{\mathrm{a}}$ and $\Delta \mathrm{H}$ increase with increasing wt $\%$ OG up to around $70 \mathrm{wt} \%$. Further increase in concentration of $\mathrm{OG}$ up to $80 \mathrm{wt} \%$ reduce $\mathrm{E}_{\mathrm{a}}$ and $\Delta \mathrm{H}$.

\section{Relationships between curing parameters and dynamic mechanical analysis and mechanical properties}

Figures 9 and 10 show the DMA of OG/DMA composites. In Figure 9 the maximum rubbery state modulus is found at $\phi=1$. As the rubbery state modulus relates directly to the network cross-link density, the maximum cross-link density is expected at $\phi=1$ (83 wt $\%$ OG and $17 \mathrm{wt} \%$ of MDA, corresponding to stoichiometric ratio), which appears in DMA as the maximum rubbery state modulus (Figure 9) and the highest $\mathrm{T}_{\mathrm{g}}$ (Figure 10).

On the other hand, fracture toughness and tensile modulus mechanical properties show the same profile with respect to $\mathrm{OG}$ content, in the sense that they exhibit maxima at $\phi \approx 0.50(\approx 70 \mathrm{wt} \%$ OG and $30 \mathrm{wt} \%$ of MDA, corresponding to an "excess" of MDA), as is shown in Figures 11 and 12, respectively.

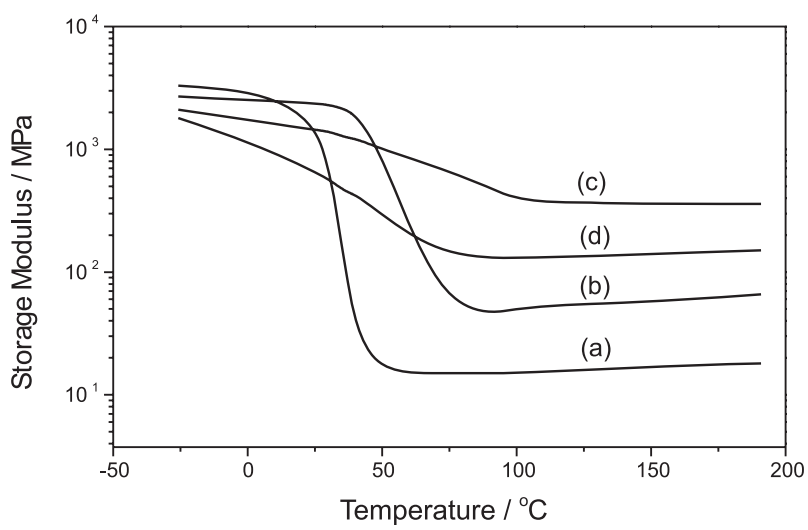

Figure 9. Storage modulus for OG/MDA composites at various OG contents (wt\%): (a) 63, (b) 73, (c) 83, (d) 91.

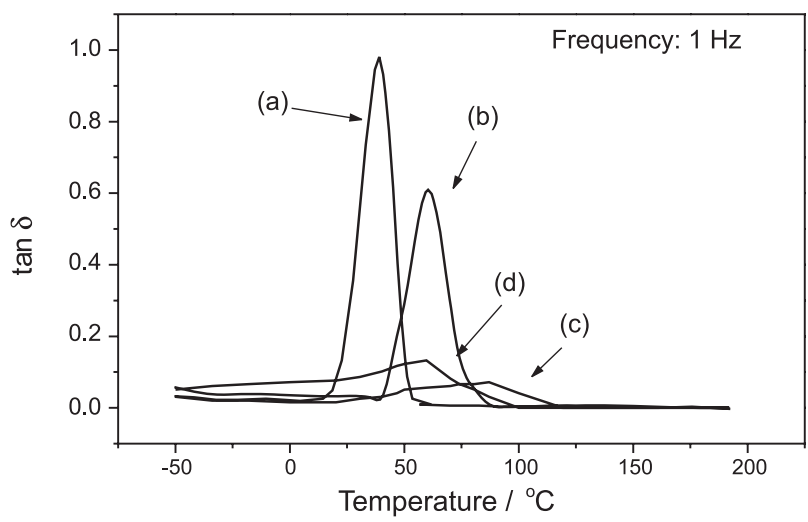

Figure 10. $\tan \delta$ for OG/MDA composites at various OG contents (wt $\%$ ): (a) 63, (b) 73, (c) 83, (d) 91 .
Thus, dynamic mechanical analysis indicates that the maximum cross-link density is obtained at $83 \mathrm{wt} \%$ OG, whereas fracture toughness and tensile modulus mechanical properties are maximized at $70 \mathrm{wt} \%$ OG.

It is known that for conventional epoxy resin, such as DGEBA, the highest cross-link densities are obtained at stoichiometries where two epoxy ring equivalents are mixed with one amine group equivalent (corresponding to stoichiometric point: the ratio of epoxy ring to amine hydrogen is $1: 1$, and $\phi=1)$. Most epoxy thermoset materials exhibit the maximum tensile modulus values for stoichiometries of $\phi=1.0$ ( $\phi$ is defined as the molar ratio of epoxy ring in conventional epoxy per amine hydrogen). Fracture toughness also increases as the amine content increases below $\phi=1$.

For the OG/MDA composites the highest cross-link density which would be obtained at $\phi=1$ ( $83 \mathrm{wt} \%$ OG) implies that the dominating structure is expected to be

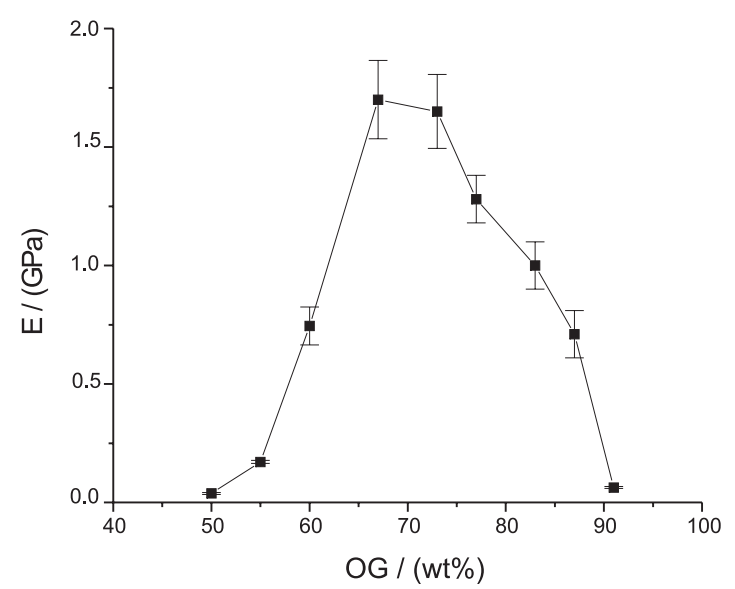

Figure 11. Tensile modulus (E) for OG/MDA composites versus OG content. Each data point represents an average of at least five samples.

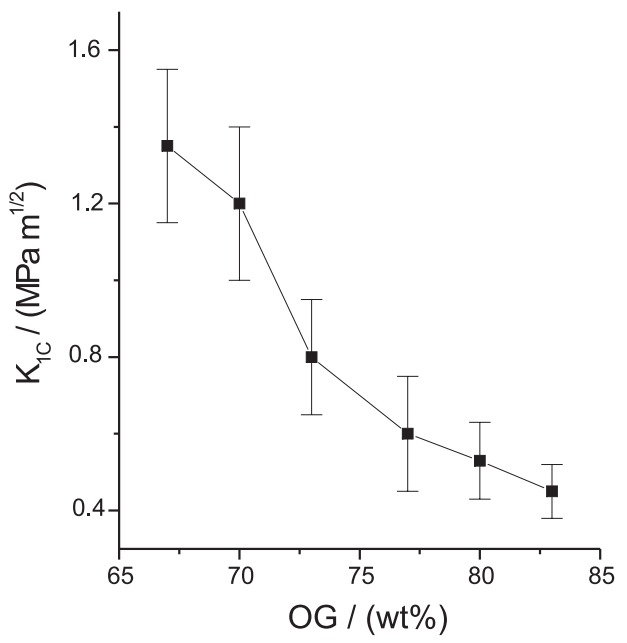

Figure 12. Fracture toughness $\left(\mathrm{K}_{1 \mathrm{C}}\right)$ for $\mathrm{OG} / \mathrm{MDA}$ composites versus $\mathrm{OG}$ content. Each data point represents an average of at least five samples. 
the one in which MDA is tetrafunctional on curing, e.g. connecting four cubes.

On the contrary, for the OG/MDA composites, the maximum modulus and fracture toughness are obtained at $\phi \approx 0.50(\approx 70 \mathrm{wt} \%$ OG), and maintains its maximum modulus up to $\phi \approx 0.40$, which are not compositions where the highest cross-linked density are reached. This implies that the best mechanical properties are provided by some degree of chain flexibility.

This can be tentatively explained based on the fact that before occurring the complete reaction and crosslink between all the amines and epoxy rings, it becomes very difficult for unreacted functional groups to find each other due to increasing of the viscosity during curing. These unreacted functional groups will remain as pendant groups. Then, for $\phi<1.0$, the excess increasing of MDA causes increased motion of organic tethers (links between cubes) by increasing the number of pendants groups and/or decreasing cross-link density. The other possibility is that the steric hindrance should be greater for bulky OG than for conventional epoxy, such as DGEBA. In this case, the reaction of the first hydrogen of the $\mathrm{NH}_{2}$ group should be favored over the second one, resulting in a uniform and densely crosslinked structure that can be obtained at $\phi \approx 0.50$. In this case, the dominating structure is expected to be the one in which MDA is bifunctional on curing (linear tethers connecting two cubes). This assumption (MDA is bifunctional connecting two cubes) seems to be favored taking into consideration that the highest values of $\Delta \mathrm{H}$ (heat of polymerization, $\mathrm{E}_{\mathrm{a}}$ (obtained from DSC), $\mathrm{E}$ (tensile modulus), and $\mathrm{K}_{1 \mathrm{C}}$ (fracture toughness), occur in a ratio of $\sim 4$ mol of $\mathrm{MDA}$ to $1 \mathrm{~mol}$ of $\mathrm{OG}$ corresponding to $\phi \approx 0.50$.

For instance, when DGEBA is cured with excess MDA the material changes from ductile to a brittle material, both tensile modulus and fracture toughness increase from $\phi=1.0$ to $\phi=0.5$, and, then, they drop significantly. ${ }^{19}$ Therefore, while epoxy resin/hardener conventional systems become brittle with excess of curing agent ("Excess" MDA is used for $\phi<1.0$ ), OG/MDA composites become rubbery. At $\phi \approx 0.14$, the modulus data of OG/ MDA cannot be measured because of the rubberlike behavior. On the other hand, for composition at $\phi>2.0$ ("Excess" OG) OG/MDA composites become viscous. Consequently, at $\phi>2.0$, the modulus of OG/MDA cannot be measured, and no data points are included in Figure 9. This behavior also reflects in the fracture toughness, and no data points for $\phi<0.45$ and $\phi>2.0$ are included, because it is practically impossible to introduce a natural crack into these samples.

\section{Conclusions}

The cure kinetic of a hybrid epoxy resin, denominated octa[dimethylsiloxypropylglycidylether] octasiloxane (OG), in presence of 3,3-methylenedianiline (MDA) as hardener, was examined by DSC technique at various experimental conditions.

The results of heat of polymerization and activation energy obtained by DSC technique show the same profile with respect to OG content, in the sense that they exhibit maxima around $70 \mathrm{wt} \%$ OG $(\phi \approx 0.50)$.

Dynamic mechanical analysis suggests that the maximum cross-link density is obtained at $83 \mathrm{wt} \%$ OG $(\phi$ $=1$, components are mixed at stoichiometric amount), whereas fracture toughness and tensile modulus mechanical properties are maximized at $70 \mathrm{wt} \%$ OG $(\phi \approx$ 0.50 ). Thus, this formulation of $\phi \approx 0.50$ containing excess of amine, is not the composition where the highest crosslinked density is reached for the OG/MDA composites. This implies that the best mechanical properties and curing parameters are provided by some degree of chain flexibility.

These results indicated that these techniques can be used to study the curing conditions of hybrid epoxy resins based on cubic silsesquioxanes. Furthermore, the results these techniques can be used to know and to understand the relationships between the structure of the networks and the final properties.

\section{Acknowledgments}

The authors are indebted to the FAPESP (process number 1997/11133-7) for financial support.

\section{References}

1. Mark, H. F.; Bikales, M. N.; Overberger, C. G.; Mengues, G.; Encyclopedia of Polymer Science and Engineering, Emulsion Polymerization to Fibers, Manufacture, John Wiley \& Sons: New York, 1986.

2. Lee, H.; Neville, K.; Handbook of Epoxy Resins, McGraw Hill: New York, 1967.

3. Mauri, A. N.; Riccardi, C. C.; Williams, R. J. J.; Polym. Bull. 2001, 45, 523.

4. Pellice, S. A.; Fasce, D. P.; Williams, R. J. J.; J. Polym. Sci. 2003, 41, 1451.

5. Smith, I. T.; Polymer 1961, 2, 95.

6. Yamini, S.; Young, R. J.; J. Mat. Sci. 1980, 5, 1814.

7. Yamini, S.; Young, R. J.; J. Mat. Sci. 1980, 15, 1823.

8. Zhang, C.; Laine, R. M.; J. Organomet. Chem. 1996, 521, 199.

9. Lee, A.; Lichtenhan, J.D.; Macromolecules 1998, 31, 4970. 
10. Rey, L.; Poisson, N.; Maazouz, A.; Sautereau, H.; J. Mat. Sci. 1999, 34, 1775.

11. Li, Z. G.; Wang, L.; Toghiani, H.; Daulton, T. L.; Koyma, K.; Pittman Jr., C.U.; Macromolecules 2001, 34, 8686.

12. Abad, M. J.; Barral, L.; Fasce, D. P.; Williams, R. J. J.; Macromolecules 2003, 36, 3128.

13. Fu, B. X.; Namani, M.; Lee, A.; Polymer 2003, 44, 7739.

14. Ni, Y.; Zheng, S.; Nie, K.; Polymer 2004, 45, 5557.

15. Voronkov, M. G.; Lavrent'yev, V. I.; Top. Curr. Chem. 1982, 102, 199.

16. Baney, R. H.; Itoh, M.; Sakakibara, A.; Suzuki, T.; Chem. Rev. 1995, 95, 1409.

17. Provatas, A.; Matisons, J. G.; Trends. Polym. Sci. 1997, 5, 327.

18. Feher, F. J.; Budzichowski, T. A.; J. Organomet. Chem. 1989 , $379,33$.

19. Laine, R. M.; Asuncion, M.; Baliat, S.; Dias Filho, N. L.; Harcup, J.; Sutorik, A. C.; Viculis, L.; Yee, A. F.; Zhang, C.; Zhu, Q. In Organic/Inorganic Hybrid Materials; Klein, L.; De Guire, M.; Lorraine, F.; Mark, J., eds.; MRS Symp. Ser. vol. 576, 1999, pp. 3-14; Dias Filho, N. L., unpublished work.

20. Laine, R. M.; Choi, J.; Lee, I.; Adv. Mat. 2001, 13, 800.

21. Choi, J.; Yee, A. F.; Laine, R. M.; Macromolecules 2003, 36, 5666.

22. Choi, J.; Tamaki, R.; KIM, S. G.; Laine, R. M.; Chem. Mat. 2003, 15, 3365.

23. Choi, J.; Kim, S. G.; Laine, R. M.; Macromolecules 2004, 37, 99.

24. Hasegawa, I.; Kuroda, K.; Kato, C.; Bull. Chem. Soc. Jap. 1986, 59, 2279.
25. Hasegawa, I.; Sakka, S.; Sugahara, Y.; Kuroda, K.; Kato, C.; J. Chem. Soc. Chem. Comm. 1989, 208.

26. Hasegawa, I.; Ishida, M.; Motojima, S.; Synth. React. Inorg., Met.-Org., Nano-Met. Chem. 1994, 24, 1099.

27. Sellinger, A.; Laine, R. M.; Chem. Mater. 1996, 8, 1592.

28. Prime, R.B. In Thermal Characterization of Polymeric Materials, $2^{\text {nd }}$ ed., Academic Press: San Diego, 1997, vol. 2, ch. 6 .

29. Varma, I. K.; Bhama, P. V. S.; J. Comp. Mat. 1986, 20, 411.

30. He, Y.; Thermochim. Acta 2001, 367, 101.

31. Rosu, D.; Cascaval, C. N.; Mustata, F.; Ciobanu, C.; Thermochim. Acta, 2002, 383, 119; Rosu, D.; Mustata, F.;Cascaval, C.N.; Thermochim. Acta, 2001, 370, 105.

32. Borchardt, H.J.; Daniels, F.; J. Am. Chem. Soc. 1956, 79, 41; Barret, K.E.J.; J. Appl. Polym. Sci. 1967, 11, 1617; Kissinger, H. E.; Anal. Chem. 1957, 29, 1702; Malek, J.; Thermochim. Acta 1992, 200, 257; Malek, J.; Thermochim. Acta 2000, 355, 239.

33. Urbaczewski, E.; Pascault, J. P.; Sautreau, H.; Riccardi, C. C.; Moschiar, S. S.; Williams, R. J. J.; J. Makromol. Chem. 1990, 191, 943; Mijovic, J.; Kim, J.; Slaby, J.; J. Appl. Polym. Sci. 1984, 29, 1449; Riccardi, C. C.; Williams, R. J. J.; J. Appl. Polym. Sci. 1986, 32, 3445.

Received: November 13, 2005

Published on the web: June 29, 2006

FAPESP helped in meeting the publication costs of this article. 